Revista Universo Contábil, ISSN 1809-3337

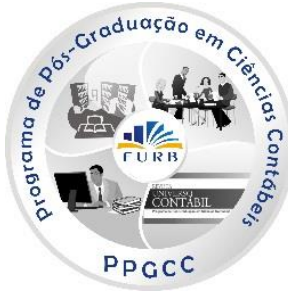

PERFIL DO PROFISSIONAL CONTÁBIL DEMANDADO PELO MERCADO DE TRABALHO: UM ESTUDO NO NORTE DO BRASIL 1

\title{
PROFILE OF ACCOUNTING PROFESSIONALS REQUIRED BY THE LABOUR MARKET: A STUDY IN NORTHERN BRAZIL
}

\section{PERFIL DE LOS PROFESIONALES DE CONTABILIDAD REQUERIDO POR EL MERCADO DE TRABAJO: UN ESTUDIO EN EL NORTE DE BRASIL}

Carla Macedo Velloso dos Santos Tamer Bacharel em Ciências Contábeis pela Universidade Federal Fluminense - UFF Endereço: Av. General Rodrigo Octávio, 3000 CEP: 69.080-005 - Manaus - AM E-mail: pitalex@gmail.com Telefone: (92) 3305-4546

\section{Clilson Castro Viana}

Bacharel em Ciências Contábeis pela Universidade Federal do Amazonas

Endereço: Av. General Rodrigo Octávio, 3000 CEP: 69.080-005 - Manaus - AM E-mail: clilson castro@hotmail.com

Telefone: (92) 3305-4546

Luiz Augusto de Carvalho Francisco Soares Mestre em Administração pela Universidade Federal de Santa Catarina Professor do Departamento de Contabilidade da Universidade Federal do Amazonas - UFAM Endereço: Av. General Rodrigo Octávio, 3000 CEP: 69.080-005 - Manaus - AM E-mail: las10@uol.com.br Telefone: (92) 3305-4546

Mariomar de Sales Lima Doutora em Engenharia de Produção pela UFRJ Professora do Departamento de Contabilidade da Universidade Federal do Amazonas - UFAM Endereço: Av. General Rodrigo Octávio, 3000 CEP: 69.080-005 - Manaus - AM

E-mail: msl@ufam.edu.br Telefone: (92) 3305-4546

\footnotetext{
${ }^{1}$ Artigo recebido em 03.02.2013. Revisado por pares em 09.09.2013. Reformulado em 27.09.2013. Recomendado para publicação em 28.09.2013 por Carlos Eduardo Facin Lavarda. Publicado em 30.09.2013. Organização responsável pelo periódico: FURB.
} 


\section{RESUMO}

Estudo recente, realizado pela Federação das Indústrias do Estado do Amazonas (FIEAM) e pelo Centro da Indústria do Estado do Amazonas (CIEAM), apontou uma expressiva carência de profissionais contábeis qualificados na Região Norte do Brasil, o que tem acarretado a importação de mão de obra de outras regiões do país. Contudo, para que os profissionais do Norte possam desenvolver sua carreira de forma eficaz, inclusive durante sua graduação, é importante identificar as demandas do mercado de trabalho local. Ante ao contexto delineado, este estudo objetivou identificar o perfil do profissional contábil demandado pelo mercado de trabalho do Norte do Brasil, segundo os anúncios de emprego divulgados em sites de recrutamento e jornais de grande circulação. Para tanto, analisou-se 690 anúncios de vagas de emprego para profissionais da área contábil, sendo que $66 \%$ eram destinados a cargos auxiliares, $22 \%$ a cargos de chefia e $11 \%$ a cargos de gerência. Para os níveis auxiliar e de chefia, os conhecimentos mais demandados foram os relacionados à contabilidade geral e tributária e tecnologia da informação. Já para o nível de gerência, o conjunto de conhecimentos de maior destaque referiu-se à contabilidade gerencial e gestão empresarial, seguido pela tecnologia da informação. Destaca-se que experiência profissional e especialização ou MBA foram altamente demandados para todos os níveis hierárquicos. Concluiu-se, por meio do ranking dos conhecimentos e habilidades mais exigidos, que o mercado de trabalho do Norte brasileiro demanda por um profissional eclético, com uma gama de conhecimentos e habilidades, contudo priorizam os conhecimentos voltados à parte operacional e dão menor ênfase aos conhecimentos ligados à tomada de decisão.

Palavras-chave: Mercado de trabalho. Profissional Contábil. Conhecimentos e habilidades. Norte do Brasil.

\section{ABSTRACT}

A recent study conducted by the Federação das Indústrias do Estado do Amazonas (FIEAM) and the Centro da Indústria do Estado do Amazonas (CIEAM), showed a significant shortage of qualified accounting professionals in Northern Brazil, which has led to the importation of hand labor from other regions of the country. However, for professionals in the North can develop your career effectively, including during his graduation, it is important to identify the demands of the local labor market. Thus, this study aimed to identify the profile of the professional accounting demanded by the labor market in Northern Brazil, according to job listings published on recruitment websites and newspapers of general circulation. Therefore, we analyzed 690 advertisements of job vacancies for accounting professionals, $66 \%$ were intended for office assistants, 22\% to leadership positions and $11 \%$ for management positions. To assistants and leaderships, the skills most in demand were general accounting and tax and information technology. To managers, the skills most in demand were the management accounting and business management, followed by information technology. Experience and MBA are highly demanded for all levels. It is concluded, through the ranking of the most demanded skills that the labor market of the North Brazilian demand for a professional eclectic, with a range of knowledge and skills, however prioritize knowledge focused on the operational side and give less emphasis to knowledge related to decision making.

Keywords: Labor market. Professional accountant. Knowledge and skills. Northern Brazil.

\section{RESUMEN}

Un estudio reciente llevado a cabo por la Federação das Indústrias do Estado do Amazonas (FIEAM) y el Centro da Indústria do Estado do Amazonas, mostró una gran escasez de profesionales contables cualificados en el norte de Brasil, que ha dado lugar a la importación de mano de obra de otras regiones del país. Sin embargo, los profesionales del Norte pueden 
desarrollar su carrera de manera eficaz, incluso durante su graduación, es importante identificar las demandas del mercado de trabajo local. Ante el contexto descrito, el presente estudio tuvo como objetivo identificar el perfil del profesional de la contabilidad exigida por el mercado de trabajo en el norte de Brasil, según las ofertas de empleo publicadas en los sitios web de reclutamiento y periódicos de circulación general. Por lo tanto, se analizaron 690 anuncios de vacantes de empleo para los profesionales de la contabilidad, el $66 \%$ fue destinado a asistentes, el $22 \%$ de puestos directivos y el $11 \%$ para los puestos de dirección. Asistir y los niveles de mando, más el conocimiento de los acusados fueron relacionada con la contabilidad general y la tecnología y la información fiscal. En cuanto al nivel de gestión, el cuerpo de conocimientos más importante se refiere a la contabilidad de gestión y dirección de empresas, seguido de tecnología de la información. Es de destacar que la experiencia y especialización o MBA son muy demandados para todos los niveles. Se concluye, a través de la clasificación de los conocimientos y habilidades más necesarias, que el mercado laboral del Norte la demanda brasileña por un ecléctico profesional, con una amplia gama de conocimientos y habilidades, sin embargo priorizar el conocimiento centrado en la parte operativa y dar menos énfasis a conocimientos relacionados con la toma de decisiones.

Palabras clave: Del mercado de trabajo. Profesional de Contabilidad. Los conocimientos y habilidades. Norte de Brasil.

\section{INTRODUÇÃO}

Recentemente, empresas de diversos países se depararam com mudanças significativas na contabilidade. No caso especifico do Brasil, com o propósito de permitir a convergência das normas contábeis adotadas aos padrões das normas do International Financial Reporting Standards - IFRS, já adotados nos principais mercados de valores mobiliários mundiais, a Lei das Sociedades por Ações - Lei $\mathrm{n}^{\circ}$ 6.404/76, contou com adequações iniciadas pela Lei $\mathrm{n}^{\circ}$ 11.638/07 e, posteriormente, pela Lei $\mathrm{n}^{\circ}$ 11.941/09.

Ainda nesse contexto, o Comitê de Pronunciamentos Contábeis (CPC), criado pela Resolução do CFC $\mathrm{n}^{\circ} 1.055 / 05$, elaborou e divulgou no ano de 2008 os primeiros pronunciamentos contábeis e orientações, alinhados com as normas internacionais de contabilidade, para atender às alterações da legislação societária. Nesse novo cenário, as empresas tiveram impactos não apenas nas práticas contábeis, mas também em seus resultados, como concluiu Santos (2011) em sua pesquisa, que visou estimar o impacto da adoção do full IFRS nos resultados do exercício de 2010 de vinte companhias brasileiras.

Além das alterações na legislação societária, as empresas tiveram que se adequar à modernização das obrigações acessórias exigidas pelo físco, como é o caso dos projetos do Sistema Público de Escrituração Digital (SPED), tema do estudo de Faria et al. (2010). Essas e outras mudanças nas práticas contábeis acarretam uma maior exigência na qualificação dos profissionais contábeis.

Assim, segundo Santos et al. (2011), para que o profissional contábil desenvolva sua carreira de forma eficaz, inclusive durante sua graduação, é importante identificar as habilidades e conhecimentos demandados pelo mercado de trabalho. Blouch, Ulrich e Michenzi (2010) apontam que o mercado quer profissionais contábeis que possuam certas habilidades, mas durante a graduação os alunos tendem a não perceber a importância disso, tendo como foco apenas as competências técnicas requeridas para a qualificação no exame de suficiência profissional.

Salienta-se que o mercado de trabalho da Região Norte do país, no que tange as sociedades de direito privado, é composto basicamente por empresas dos ramos comercial e industrial, com destaque para o Estado do Amazonas que possui um pólo industrial em sua capital (IBGE, 2010). Mencionado pólo denomina-se Pólo Industrial de Manaus (PIM) e 
compõe-se por mais de 600 indústrias, tanto nacionais quanto multinacionais, gerando mais de 100 mil empregos para o Estado. Contudo, pesquisa realizada pela Federação das Indústrias do Estado do Amazonas (FIEAM) e pelo Centro da Indústria do Estado do Amazonas (CIEAM) em 2012, identificou uma expressiva carência de profissionais qualificados, inclusive na área contábil, o que tem resultado na importação de mão de obra de outras regiões do país, apesar de haverem mais de vinte mil contadores registrados nos conselhos regionais do Norte do Brasil.

Frente a esse fato, os profissionais contábeis da Região Norte precisam estar atentos às exigências do mercado de trabalho, procurando a qualificação profissional. Segundo Machado e Nova (2008), que identificaram os conhecimentos específicos requisitados pelas empresas de São Paulo vencedoras do Anuário da Revista Exame "Maiores e Melhores" do ano de 2005, as empresas reconhecem que quanto maior o grau de conhecimento do profissional, menor serão os gastos com treinamentos, daí a preferência pela maior qualificação.

Estudos como o de Peleias el al. (2008), Pires, Ott e Damacena (2009) e Santos et al. (2011), identificaram o perfil do profissional contábil requerido pelo mercado de trabalho de localidades diversas do país, contudo, no Norte do Brasil estudos científicos voltados à essa temática ainda são escassos, apesar de sua importância para o desenvolvimento dos profissionais, das empresas e, consequentemente, da sociedade dessa Região. Diante do exposto, esta pesquisa visa responder à seguinte questão: Qual é o perfil do profissional contábil demandado pelo mercado de trabalho do Norte do Brasil, segundo os anúncios de emprego divulgados em sites de recrutamento e jornais de grande circulação?

Sendo assim, o objetivo geral deste estudo consiste em identificar o perfil do profissional contábil demandado pelo mercado de trabalho do Norte do Brasil, segundo os anúncios de emprego divulgados em sites de recrutamento e jornais de grande circulação. Espera-se que os resultados apurados possam servir de parâmetros para a elaboração ou reestruturação das grades curriculares dos cursos de Ciências Contábeis do Norte do Brasil, objetivando seu alinhamento com a demanda do mercado de trabalho. Além disso, espera-se que os resultados possam contribuir com os estudantes e profissionais da área contábil, oferecendo-lhes subsídios para a busca de ações que possam desenvolver e aprimorar os conhecimentos e habilidades requeridos pelas empresas localizadas na região.

$\mathrm{O}$ artigo divide-se em cinco seções, incluída a parte introdutória. $\mathrm{Na}$ seção dois apresenta-se a revisão da literatura, na qual examinam-se as pesquisas sobre o perfil, habilidade e competências do profissional contábil. Na seção três descrevem-se a metodologia e os dados aplicados para a realização da pesquisa. Na quarta parte do trabalho analisam-se os resultados da pesquisa, destacando, sintetizando e analisando os principais pontos observados. Por fim, apontam-se a conclusão do estudo, seguida das sugestões para futuras pesquisas.

\section{PERFIL, HABILIDADES E COMPETÊNCIAS DO PROFISSIONAL CONTÁBIL}

O Ministério da Educação (MEC), por meio da Resolução CNE/CES 10/2004, que institui as diretrizes curriculares nacionais para o curso de graduação em ciências contábeis, dispõe que as Instituições de Ensino Superior (IES) devem estabelecer em seus Projetos Pedagógicos o perfil profissional esperado para o formando, em termos de competências e habilidades. Segundo Leal, Soares e Sousa (2008), essas competências e habilidades podem ser resumidas em visão sistêmica da atividade contábil, aplicação adequada da legislação contábil, desenvolvimento, análise e implantação de sistemas de informação contábil e de controle gerencial, ética, entre outras.

Também preocupados com o perfil dos futuros profissionais, Chaker e Abdullah (2012), realizaram pesquisa com o objetivo de avaliar quais habilidades e conhecimentos os alunos do Instituto de Economia, Gestão e Pesquisa Estratégica do Cazaquistão adquiriram durante o curso de graduação em Ciências Contábeis. Após entrevista com 77 alunos, concluíram que 
estes possuíam habilidades e conhecimentos voltados à ética profissional, relacionamento interpessoal e de comunicação, contabilidade financeira e habilidades de gestão. Os pesquisadores concluíram também que as habilidades relacionadas ao ambiente de negócios, contabilidade gerencial e contabilidade tributária foram as mais escassas, refletindo a necessidade de ações para suprir essa lacuna.

Todavia, também faz-se necessário conhecer o perfil, as habilidades e competências dos profissionais contábeis demandados pelo mercado de trabalho. Diante disso, diversas pesquisas, nacionais e internacionais, tiveram esse tema como foco, como no estudo de Cory e Huttenhoff (2011), com a finalidade de identificar os tópicos que deveriam ser abordados nos cursos de graduação em ciências contábeis dos Estados Unidos. Com a pesquisa, obtiveram 170 respostas de contadores que atuavam em empresas privadas e concluíram que as habilidades mais importantes para o profissional contábil eram pensamento crítico, boa comunicação escrita e oral, bom relacionamento interpessoal, facilidade em trabalhar em equipe, espírito de liderança, profissionalismo e busca por educação continuada. Além disso, também observaram que os conhecimentos mais importantes adquiridos na graduação eram contabilidade intermediária, ética, contabilidade avançada, contabilidade gerencial, auditoria, ambiente de negócios e contabilidade tributária.

Similarmente, Cory e Pruske (2012), com o objetivo de examinar o ponto de vista dos profissionais de contabilidade dos Estados Unidos sobre as competências e conhecimentos que os alunos deveriam buscar antes de entrarem no mercado de trabalho, realizaram uma pesquisa com 464 profissionais contábeis experientes e concluíram que seria fundamental para a futura empregabilidade dos alunos os conhecimentos sobre o pacote Office, Windows, terem criatividade em solucionar problemas, sensibilização para questões éticas e entenderem as terminologias de informática.

Já Souza e Vergilino (2012), com o objetivo de investigar a aderência existente entre a formação oferecida por IES do Rio Grande do Sul e as exigências do mercado de trabalho do profissional contábil, analisaram anúncios de oferta de emprego publicados por headhunters na Revista Exame - janeiro de 2008 a dezembro de 2009 - e utilizaram questionário endereçado aos coordenadores de cursos de Ciências Contábeis. Concluíram, portanto, que o ensino oferecido pela maioria das IES atendiam às demandas de mercado para o profissional contábil. Verificaram que os anúncios buscavam profissionais cada vez mais capacitados, com conhecimentos em IFRS, consolidação de demonstrações, análise, conversão, relatórios para investidores estrangeiros, legislação societária, tecnologia da informação relacionada à rotina contábil, conhecimento em SPED contábil e fiscal, entre outros. Também apresentaram outros conhecimentos e habilidades exigidos pelo mercado, como fluência em línguas estrangeiras, pró-atividade, comprometimento e trabalho em equipe sob pressão.

Em estudo semelhante, Santos et. al (2011), com o objetivo de avaliar se a formação acadêmica em Ciências Contábeis oferecida pelas IES de Curitiba (PR) condizia com as demandas do mercado de trabalho na área contábil, analisaram os dados coletados nos anúncios de emprego e nas grades curriculares do curso de Ciências Contábeis das IES e concluíram que a formação dos profissionais contábeis oferecida pelas IES, condizia com as necessidades do mercado. Concluíram, ainda, que as exigibilidades das empresas pesquisadas eram relacionadas à experiência, conhecimentos em contabilidade e legislação societária e tributária, tecnologia da informação, contabilidade gerencial e gestão empresarial, domínio de outros idiomas, Normas Internacionais de Contabilidade, entre outros.

Contudo, para Machado e Nova (2008), somente a graduação em ciências contábeis não basta para que o egresso tenha uma posição de destaque no mercado de trabalho. Com objetivo de avaliar se os conhecimentos adquiridos pelos formandos do curso de Ciências Contábeis da cidade de São Paulo atendiam à demanda do mercado, realizaram pesquisa de campo com 120 alunos das principais IES da cidade e, posteriormente, identificaram os conhecimentos 
específicos requisitados pelas empresas de São Paulo vencedoras do Anuário da Revista Exame "Maiores e Melhores" do ano de 2005. Concluíram que, pelo alto grau de exigência do mercado quanto aos conhecimentos específicos, os alunos pesquisados não se consideravam aptos a atender às expectativas das empresas. Concluíram também que os conhecimentos específicos mais demandados pelas empresas pesquisadas foram as Práticas Contábeis Nacionais e Internacionais e Raciocínio Lógico e Matemático.

Em estudo similar, Diaconu et al. (2011) realizaram pesquisa com objetivo de investigar se os conhecimentos contábeis profissionais e pessoais desenvolvidos nas universidades da Romênia eram compatíveis com a demanda do mercado daquele país. Por meio de coleta de anúncios em sites de vagas de emprego, concluíram que os conhecimentos assimilados durante os programas de estudo das universidades eram necessários, mas não suficientes para suprir a demanda do mercado de trabalho. Entre as principais exigências das empresas romenas para cargos contábeis executivos estão os conhecimentos teóricos em síntese e análise contábil e em normas internacionais - IFRS.

Nota-se a preocupação das IES em conhecer o mercado para adequar seus currículos e formarem profissionais cada vez mais capacitados. Contudo, os profissionais já formados também necessitam conhecer o mercado para que possam buscar capacitação eficiente e melhorar sua empregabilidade.

Assim, Oro et al. (2009), visando investigar o perfil de competências requerido pelo mercado nacional para o profissional da controladoria nos níveis operacional, gerencial e estratégico, analisaram 373 anúncios de oferta de trabalho de três sites especializados de recrutamento e seleção de recursos humanos em agosto e setembro de 2006 e concluíram que o perfil do profissional de controladoria nos anúncios de ofertas de trabalho indicava a necessidade de diferentes conhecimentos, de acordo com os níveis pesquisados. Contudo, para os três níveis, verificou-se que a principal demanda de conhecimentos eram relacionados à contabilidade societária, análise empresarial e US GAAP. Concluíram, também, que em todos os níveis havia a necessidade de dominar o inglês, possuir tempo de experiência profissional de 1 a 2 anos para o nível operacional e de 5 a 6 anos nos demais níveis.

Pires, Ott e Damascena (2009) analisaram o perfil do profissional contábil requerido pelo mercado de trabalho da Região Metropolitana de Porto Alegre (RS) através da análise de 939 ofertas de emprego coletadas no período de janeiro a setembro de 2007. A análise apontou a demanda por profissionais com conhecimentos voltados, principalmente, para a contabilidade societária, legislação societária e tributária, além de experiência prévia e um amplo conjunto de habilidades e atitudes.

Diante das recentes mudanças nas práticas contábeis, Faria e Queiroz (2009) realizaram pesquisa com objetivo de identificar as demandas do mercado de trabalho de contadores com conhecimentos voltados à Contabilidade Internacional. Assim, analisaram anúncios de ofertas de emprego na cidade de São Paulo nos anos de 2007 e 2008 e concluíram que a demanda por conhecimentos voltados aos padrões internacionais de contabilidade, como o americano US GAAP e pelo IFRS, apresentava-se expressiva, levando em consideração as várias áreas de atuação dos profissionais. Constataram, ainda, que os demais conhecimentos e habilidades demandados eram relacionados à informática, desenvolvimento de relatórios gerenciais e língua estrangeira, principalmente a inglesa.

Também por meio da análise de anúncios de vagas de empregos, Peleias et al. (2008) identificaram e analisaram o perfil profissiográfico requerido pelo mercado de trabalho para os profissionais de contabilidade na Região Metropolitana de São Paulo. Concluíram que havia uma forte demanda por experiência profissional, além de conhecimentos em contabilidade societária, tributária e legislação, contabilidade gerencial e gestão empresarial e tecnologia da informação. 
Nos Estados Unidos, McMullen e Sanchez (2010) realizaram pesquisa que objetivou analisar a percepção da comunidade profissional quanto às habilidades necessárias para os contadores forenses americanos, bem como os requisitos considerados importantes para a profissão. Após coletar os dados da pesquisa, concluiram que dentre as características mais importantes para os contadores forenses estavam persistência, raciocínio estratégico e bom relacionamento interpessoal. Quanto aos conhecimentos necessários, destacaram-se a contabilidade básica, resolução de problemas, análise de dados, técnicas de entrevista e informática.

Ante aos estudos supracitados, nota-se que os conhecimentos em informática, além de outros, estão sendo fortemente solicitados pelo mercado. Sob esse foco, o estudo de Rai (2012) analisou a lacuna existente entre o conhecimento e a pecepção da importância da tecnologia da informação (TI) entre os profissionais de contabilidade na Austrália. Os resultados indicaram que os contadores possuíam elevado conhecimento em e-mail e software de comunicação, planilha eletrônica e em ferramentas de busca da Internet. Contudo, o conhecimento em TI apresentou-se menor que a importância percebida entre os contadores australianos. Dos conhecimentos mais relevantes, foram citados o sistema Office, sistemas contábeis e sistemas de gestão de risco.

Constata-se, portanto, que o mercado de trabalho está demandando cada vez mais dos profissionais contábeis experiência, idiomas, conhecimentos atualizados, habilidades e atitudes, o que reflete a importância da busca por educação continuada. Segundo Kavanagh et al. (2010), que estudaram o papel das universidades e dos empregadores no desenvolvimento de competências técnicas e não-técnicas dos profissionais de contabilidade da Austrália, seria improvável que as universidades pudessem satisfazer a todos os atributos requeridos pelo mercado, dada a infinita variedade de empregadores. Assim, as instituições de ensino, empresas e órgãos de classe deveriam reavaliar suas abordagens para que fossem ofertados cursos de pós-graduação que atendessem às exigências do mercado.

\section{METODOLOGIA E DADOS}

Visando alcançar o objetivo proposto, o estudo tomou como referência as pesquisas de Faria e Queiroz (2009); Oro et al. (2009); Pires, Ott e Damacena (2009); Diaconu et al. (2011) e Souza e Vergilino (2012), os quais usaram pesquisa documental primária de caráter quantitativo, por meio de anúncios de vagas de emprego destinadas aos profissionais contábeis, sendo esse o procedimento mais adequado à presente pesquisa pela acessibilidade, já que o estudo foi realizado em todos os estados da Região Norte do Brasil.

Dessa forma, quanto aos objetivos, a pesquisa caracterizou-se como de natureza descritiva, conforme Souza e Vergilino (2012), que investigaram a aderência existente entre a formação oferecida pelos cursos de Ciências Contábeis das IES do Rio Grande do Sul e as exigências do mercado de trabalho. Caracteriza-se, portanto, como uma pesquisa positivista por apenas descrever "como as coisas são" e não "como as coisas devem ser", como na pesquisa normativista (STARKE JUNIOR; FREITAG; CROZATTI, 2006).

A pesquisa também usou o procedimento bibliográfico e de análise de conteúdo. Pesquisa bibliográfica por definir as variáveis e tópicos literários relacionados ao tema, como Faria e Queiroz (2009), quando descreveram sobre os padrões contábeis internacionais - IFRS e sobre a formação do profissional contábil. Pesquisa de análise de conteúdo por identificar o que está sendo dito a respeito de determinado tema (VERGARA, 2010). Assim como no estudo de Peleias et al. (2008), foi usada para tabular os conhecimentos e habilidades demandados nos anúncios publicados.

Em relação à abordagem, como Cardoso, Souza e Almeida (2006) identificando o perfil do contador na atualidade, aplicou-se também o estudo quantitativo, por utilizar-se da estatística descritiva, mediante a quantificação de freqüência e da participação relativa em percentual. 
Carla Macedo Velloso dos Santos Tamer - Clilson Castro Viana - Luiz Augusto de Carvalho Francisco Soares Mariomar de Sales Lima

O critério amostral foi o não probabalístico, por acessibilidade e conveniência, tendo sido escolhidos, do número de ofertas de empregos na área de Ciências Contábeis no Norte do Brasil, uma amostra de 690 anúncios de vagas de trabalho para profissionais que concluíram ou que cursam a graduação em ciências contábeis, coletados de dois sites especializados em recrutamento e seleção de recursos humanos e de três jornais de grande circulação em estados da Região Norte brasileira. Critério similar ao usado por Pires, Ott e Damacena (2009), para analisar o perfil do profissional contábil requerido pelo mercado de trabalho de Porto Alegre (RS).

Os sites de pesquisa foram o Catho On Line e Indeed, acessados em 14 de outubro de 2012, onde localizaram-se 185 vagas para profissionais contábeis em todos os estados do Norte. Já os anúncios em classificados foram os publicados nas edições de domingo, de 04 de março a 14 de outubro do ano de 2012, dos seguintes jornais: A Crítica (AM), Diário do Pará (PA) e Gazeta do Acre (AC), nos quais foram coletados 495 anúncios no total.

Após a coleta, os dados foram tabulados na planilha eletrônica Microsoft Excel®, baseado na metodologia utilizada por Peleias et al. (2008) e Pires, Ott e Damacena (2009): segundo o porte da empresa; segundo a origem da empresa; segundo o nível hierárquico da vaga - Quadro 1; e segundo os conhecimentos e habilidades requisitados na vaga - Quadro 2.

Quadro 1: Nível Hierárquico

\begin{tabular}{|l|l|}
\hline 1- Gerência & Diretoria, Gerência, Controller e outros cargos de gerência para profissionais de Contabilidade. \\
\hline 2- Chefia & Contador, Chefe, Encarregado, Supervisor, Coordenador e Técnico. \\
\hline 3- Auxiliar & $\begin{array}{l}\text { Estagiário, Auxiliar, Assistente e Analista de Contabilidade, ou de setores ligados à } \\
\text { Contabilidade. }\end{array}$ \\
\hline
\end{tabular}

Fonte: Peleias et al. (2008)

\section{Quadro 2: Conhecimentos e habilidades}

\begin{tabular}{|c|c|}
\hline $\begin{array}{l}\text { 1- Contabilidade Geral e } \\
\text { Tributária }\end{array}$ & $\begin{array}{l}\text { Classificação, conciliação e análise contábil, elaboração de demonstrações } \\
\text { contábeis, legislação tributária, inclusive sobre a Zona Franca de Manaus, } \\
\text { escrituração fiscal, abertura e encerramento de empresas, apuração de impostos, } \\
\text { cumprimento de obrigações tributárias principais e acessórias. }\end{array}$ \\
\hline $\begin{array}{l}\text { 2- Contabilidade gerencial e } \\
\text { gestão empresarial }\end{array}$ & $\begin{array}{l}\text { Planejamento e controle, análise de demonstrações contábeis, custos, fluxo de } \\
\text { caixa, elaboração de relatórios gerenciais, avaliação de desempenho, sistemas de } \\
\text { informação gerencial, controladoria, orçamentos e visão global da empresa. }\end{array}$ \\
\hline $\begin{array}{l}\text { 3- Normas Contábeis } \\
\text { Internacionais e } \\
\text { convergência das normas } \\
\text { brasileiras }\end{array}$ & $\begin{array}{l}\text { IFRS, US-GAAP, FASB, IASC, Lei Sarbanes-Oxley, CPCs, Avaliação de ativos, } \\
\text { Lei }{ }^{\circ} 11.638 / 07 \text {, Lei no } 11.941 / 09 .\end{array}$ \\
\hline 4- Tecnologia da informação & $\begin{array}{l}\text { Planilhas eletrônicas e processadores de textos, sistemas integrados ERP, sistemas } \\
\text { de simulação, elaboração e acompanhamento orçamentário, Nota Fiscal } \\
\text { Eletrônica, SPED (fiscal e contábil) e os demais conhecimentos ligados à } \\
\text { tecnologia da informação. }\end{array}$ \\
\hline $\begin{array}{l}\text { 5- Áreas não específicas da } \\
\text { Contabilidade }\end{array}$ & $\begin{array}{l}\text { Compras, Recursos Humanos, Contas a Pagar, Contas a Receber, Produção, } \\
\text { Logística e Marketing. }\end{array}$ \\
\hline 6- Idiomas & Domínio de outros idiomas como requisitos indispensáveis para preencher a vaga. \\
\hline 7- Outros & $\begin{array}{l}\text { Conhecimentos e características não abordados acima: trabalhar em equipe, } \\
\text { liderança, atuar sob pressão, apresentações, comunicação oral e escrita, possuir } \\
\text { especialização ou MBA, CNH, disponibilidade, entre outros. }\end{array}$ \\
\hline 8- Experiência profissional & Abrange as ofertas de emprego que pedem experiência anterior na área de atuação. \\
\hline
\end{tabular}

Para a análise dos dados foi usado tratamento estatístico e apresentação por meio de quadros, tabelas e gráficos, a fim de demonstrar a frequiência que os conhecimentos referentes às normas contábeis internacionais e à convergência das normas contábeis brasileiras são demandados pelo mercado de trabalho do Norte do Brasil. A partir da análise das freqüências 
também foi possível delinear o perfil do profissional contábil, por meio do ranking dos conhecimentos e habilidades requisitados por esse mercado.

\section{ANÁLISE DOS RESULTADOS}

A análise dos dados foi agrupada em seis seções. A primeira diz respeito à distribuição do número de anúncios por Estado. A segunda seção versa sobre o número de vagas e respectivos cargos por Estado e respectivos conhecimentos demandados. A terceira seção trata das espécies de vagas por porte das empresas. A quarta seção contém as vagas e respectivos cargos ofertados por empresas multinacionais. A quinta seção trata das espécies de vagas por nível hierárquico. E a sexta seção traz o numero de vagas ofertado na área contábil disponíveis para profissionais com outro tipo de formação.

\subsection{Distribuição do número de anúncios por Estado}

Conforme visualiza-se na Tabela 1, foram coletados 690 anúncios de vagas de empregos nos 7 estados do Norte do Brasil, sendo 2 de Roraima, 6 do Amapá, 9 de Tocantins, 15 de Rondônia, 16 do Acre, 242 do Amazonas e 400 do Pará.

O baixo número de anúncios dos Estados de Roraima, Amapá e Acre pode ser explicado pela quantidade de empresas sediadas nesses Estados. Segundo estudo do IBGE (2010), o Estado de Roraima possuía apenas 6.502 empresas, o Amapá possuía 8.824 e o Acre 10.081 empresas. Contudo, esse entendimento não se aplica aos Estados de Tocantins e de Rondônia, por possuírem no ano de 2010 mais de 26 mil e 34 mil empresas, respectivamente. Nesses casos, o baixo número de anúncios pode ter sido ocasionado pela falta da versão online dos jornais de maior circulação. Corrobora com essa dedução a pesquisa de Oro et al. (2009), onde também foi percebida a escassez de anúncios de vagas de emprego para profissionais de controladoria disponíveis na internet para a Região Norte do Brasil.

Já os Estados do Pará e Amazonas apresentaram uma quantidade de anúncios compatíveis com o número de empresas privadas localizadas em seus territórios. Segundo o IBGE (2010), Pará é o estado da Região Norte brasileira que apresenta o maior número de empresas privadas, correspondendo a 39\% das empresas da Região, seguido do Estado do Amazonas, que sedia 19\%.

Tabela 1 - Anúncios coletados por Estado

\begin{tabular}{|c|c|c|c|c|}
\hline Estado & Fonte & Quant. por fonte & Total & $\%$ \\
\hline \multirow{2}{*}{ Roraima } & Catho & 0 & \multirow{2}{*}{2} & \multirow{2}{*}{$0,3 \%$} \\
\hline & Indeed & 2 & & \\
\hline \multirow{2}{*}{ Amapá } & Catho & 2 & \multirow{2}{*}{6} & \multirow{2}{*}{$0,9 \%$} \\
\hline & Indeed & 4 & & \\
\hline \multirow{2}{*}{ Tocantins } & Catho & 0 & \multirow{2}{*}{9} & \multirow{2}{*}{$1,3 \%$} \\
\hline & Indeed & 9 & & \\
\hline \multirow{2}{*}{ Rondônia } & Catho & 4 & \multirow{2}{*}{15} & \multirow{2}{*}{$2,2 \%$} \\
\hline & Indeed & 11 & & \\
\hline \multirow{3}{*}{ Acre } & Jornal - A Gazeta do & 14 & \multirow{3}{*}{16} & \multirow{3}{*}{$2,3 \%$} \\
\hline & Catho & 1 & & \\
\hline & Indeed & 1 & & \\
\hline \multirow{3}{*}{ Amazonas } & Jornal - A Crítica & 161 & \multirow{3}{*}{242} & \multirow{3}{*}{$35,1 \%$} \\
\hline & Catho & 47 & & \\
\hline & Indeed & 34 & & \\
\hline \multirow{3}{*}{ Pará } & Jornal - Diário do Pará & 321 & \multirow{3}{*}{400} & \multirow{3}{*}{$58,0 \%$} \\
\hline & Catho & 27 & & \\
\hline & Indeed & 52 & & \\
\hline
\end{tabular}

Fonte: Dados da pesquisa. 
Segundo os dados, $72 \%$ dos anúncios coletados foram advindos da versão online dos classificados dos jornais de grande circulação dos estados do Acre, Pará e Amazonas, contra $28 \%$ de anúncios dos sites especializados em classificados de currículos e empregos. Esse fato pode indicar que algumas empresas queiram atingir profissionais de outras regiões do país, contudo, em sua maioria, a preferência é por profissionais locais.

\subsection{Vagas/cargos e conhecimentos exigidos por Estado}

No Quadro 3 pode-se observar uma síntese dos principais conhecimentos exigidos pelo mercado de trabalho de cada um dos Estados do Norte Brasileiro, segregados pelo nível hierárquico.

Quadro 3 - Conhecimentos mais exigidos por Estado

\begin{tabular}{|c|c|c|c|c|c|c|}
\hline \multirow[b]{2}{*}{ Estado } & \multicolumn{2}{|r|}{ AUXILIAR } & \multicolumn{2}{|r|}{ CHEFIA } & \multicolumn{2}{|r|}{ GERÊNCIA } \\
\hline & $\%$ & $\begin{array}{c}\text { Conhecimentos mais } \\
\text { exigidos }\end{array}$ & $\%$ & $\begin{array}{l}\text { Conhecimentos mais } \\
\text { exigidos }\end{array}$ & $\%$ & $\begin{array}{c}\text { Conhecimentos mais } \\
\text { exigidos }\end{array}$ \\
\hline Roraima & $100 \%$ & $\begin{array}{c}\text { Tecnologia da } \\
\text { informação e áreas } \\
\text { não específicas da } \\
\text { Contabilidade. }\end{array}$ & 0 & - & 0 & - \\
\hline Amapá & $100 \%$ & $\begin{array}{c}\text { Contabilidade geral e } \\
\text { tributária e } \\
\text { tecnologia da }\end{array}$ & 0 & - & 0 & - \\
\hline Tocantins & $67 \%$ & $\begin{array}{c}\text { Contabilidade geral e } \\
\text { tributária e áreas não } \\
\text { específicas da } \\
\text { Contabilidade. }\end{array}$ & $11 \%$ & $\begin{array}{c}\text { Contabilidade geral e } \\
\text { tributária. }\end{array}$ & $22 \%$ & $\begin{array}{c}\text { Áreas não } \\
\text { específicas da } \\
\text { contabilidade e } \\
\text { idiomas. }\end{array}$ \\
\hline Rondônia & $40 \%$ & $\begin{array}{l}\text { Contabilidade geral e } \\
\text { tributária, tecnologia } \\
\text { da informação e áreas } \\
\text { não específicas da } \\
\text { Contabilidade. }\end{array}$ & $47 \%$ & $\begin{array}{c}\text { Tecnologia da } \\
\text { informação e } \\
\text { Contabilidade geral e } \\
\text { tributária. }\end{array}$ & $13 \%$ & $\begin{array}{c}\text { Contabilidade geral e } \\
\text { tributária e } \\
\text { Contabilidade } \\
\text { gerencial. }\end{array}$ \\
\hline Acre & $69 \%$ & $\begin{array}{l}\text { Contabilidade geral e } \\
\text { tributária, tecnologia } \\
\text { da informação e áreas } \\
\text { não específicas da } \\
\text { Contabilidade. }\end{array}$ & $6 \%$ & $\begin{array}{c}\text { Contabilidade geral e } \\
\text { tributária. }\end{array}$ & $25 \%$ & $\begin{array}{c}\text { Áreas não } \\
\text { específicas da } \\
\text { Contabilidade. }\end{array}$ \\
\hline Amazonas & $63 \%$ & $\begin{array}{c}\text { Contabilidade geral e } \\
\text { tributária e } \\
\text { tecnologia da } \\
\text { informação. }\end{array}$ & $32 \%$ & $\begin{array}{l}\text { Contabilidade geral e } \\
\text { tributária e tecnologia } \\
\text { da informação. }\end{array}$ & $5 \%$ & $\begin{array}{c}\text { Contabilidade } \\
\text { gerencial, idiomas, } \\
\text { Contabilidade geral e } \\
\text { tributária e } \\
\text { tecnologia da } \\
\text { informação. }\end{array}$ \\
\hline Pará & $69 \%$ & $\begin{array}{l}\text { Contabilidade geral e } \\
\text { tributária, tecnologia } \\
\text { da informação e áreas } \\
\text { não específicas da } \\
\text { Contabilidade. }\end{array}$ & $17 \%$ & $\begin{array}{c}\text { Contabilidade geral e } \\
\text { tributária, áreas não } \\
\text { específicas da } \\
\text { Contabilidade, } \\
\text { Contabilidade } \\
\text { gerencial. }\end{array}$ & $14 \%$ & $\begin{array}{l}\text { Contabilidade } \\
\text { gerencial e } \\
\text { tecnologia da } \\
\text { informação. }\end{array}$ \\
\hline
\end{tabular}

Fonte: Dados da pesquisa.

Nota-se que nos Estados de Roraima e Amapá, todos os anúncios analisados solicitavam profissionais do nível auxiliar, com expressiva exigência de experiência profissional. Os conhecimentos mais exigidos em Roraima foram em tecnologia da informação e em áreas não específicas da contabilidade, mais precisamente em contas a pagar e a receber. Já no Amapá o 
conhecimento mais exigido foi a contabilidade geral e tributária, em $100 \%$ dos anúncios, seguida pela tecnologia da informação, em 33\% e contabilidade gerencial, em $17 \%$.

Dos anúncios coletados do Estado de Tocantins, $67 \%$ referiam-se ao nível auxiliar, $11 \%$ de chefia e $22 \%$ de gerência. Em $56 \%$ das vagas eram exigidos conhecimentos referentes à contabilidade geral e tributária, $44 \%$ a áreas não específicas à contabilidade e $11 \%$ à tecnologia da informação. Destaca-se, ainda, que em $89 \%$ dos anúncios era exigida experiência profissional.

Em Rondônia, ao contrário dos demais estados, a maioria das vagas disponíveis referiase à chefia, correspondendo a $47 \%$ dos anúncios analisados, seguido de $40 \%$ para o nível auxiliar, e de $13 \%$ para o nível de gerência. Dos conhecimentos, os mais exigidos foram referente à tecnologia da informação, em $67 \%$ dos anúncios, e contabilidade geral e tributária em $60 \%$. Áreas não específicas da contabilidade foram solicitadas em $40 \%$ das vagas, contabilidade gerencial em $13 \%$ e as normas contábeis internacionais e convergência das normas brasileiras em $7 \%$ dos anúncios. $73 \%$ das vagas exigiam experiência profissional anterior, contudo, apenas $7 \%$ solicitavam algum tipo de habilidade, no caso, bom relacionamento interpessoal.

Já para o Acre, $69 \%$ dos anúncios referiam-se ao nível auxiliar, 25\% para gerência e $6 \%$ para chefia. $56 \%$ das vagas exigiam conhecimentos em áreas não específicas da contabilidade, $50 \%$ em contabilidade geral e tributária e $31 \%$ em tecnologia da informação, contudo não foram localizados anúncios solicitando profissionais com conhecimento em contabilidade gerencial e em normas internacionais. Assim como nos demais estados, a exigência por experiência profissional se mostrou expressiva, correspondendo a $88 \%$ das vagas.

No Estado do Amazonas, a maioria das vagas eram destinadas para o nível auxiliar, correspondendo a $63 \%$, seguida de $32 \%$ para os cargos de chefia e $5 \%$ para a gerência. O grupo de conhecimentos mais solicitado foi o referente à contabilidade geral e tributária, em $77 \%$ dos anúncios, sendo sucedido por conhecimentos em tecnologia da informação em 58\%, contabilidade gerencial em $27 \%$ e em áreas não específicas à contabilidade em $14 \%$. Foram encontradas exigências em conhecimentos relativos às normas contábeis internacionais em $7 \%$ dos anúncios da amostra e para $71 \%$ das vagas eram exigidas experiência profissional. Dentro das maiores solicitações dos profissionais destacam-se a especialização ou MBA, a proatividade, o bom relacionamento interpessoal, o espírito de liderança e o comprometimento.

Para o Estado do Pará, o maior número de vagas referiu-se ao nível auxiliar em 69\%, seguido pelo nível de chefia em $17 \%$ e pelo nível de gerência em $14 \%$ dos anúncios da amostra. Contabilidade gerencial lidera o grupo de conhecimentos, em $58 \%$ das vagas, seguida pelo grupo da tecnologia da informação, em $48 \%$, por áreas não específicas da contabilidade, em $41 \%$ e contabilidade gerencial, em $31 \%$. Foram exigidos, em $5 \%$ dos anúncios, conhecimentos do grupo relativo às normas contábeis internacionais e em $81 \%$ experiência profissional.

Em resumo, percebe-se uma expressiva proporção de anúncios de vagas voltadas para o nível auxiliar nos estados analisados. Isso demonstra que, apesar das especificidades geográficas, econômicas e sociais de cada um deles, o profissional em início de carreira ainda é mais demandado pelo mercado de trabalho (FARIA; QUEIROZ, 2009). Além disso, também houve similaridade entre os conhecimentos mais exigidos nos níveis auxiliar e chefia, apresentando distinções apenas no nível de gerência.

\subsection{Vagas/cargos por porte das empresas}

Dos anúncios pesquisados, 188 divulgaram o porte da empresa, correspondendo a $27,25 \%$ da amostra. Desses, $30 \%$ são advindos de empresas de pequeno ou médio porte e $70 \%$ de empresas de grande porte. Conforme a Tabela 2, dos 57 anúncios que divulgaram ser de empresas de pequeno ou médio porte, $82 \%$ solicitavam profissionais de nível auxiliar, $11 \%$ de nível de chefia e 7\% de nível de gerência. Segundo Faria e Queiroz (2009), isso demonstra que 
as pequenas e médias empresas demandam um maior número de profissionais em fase inicial de carreira, apesar de exigirem experiência profissional.

Já dos anúncios provenientes de empresas de grande porte, $72 \%$ solicitavam profissionais de nível auxiliar, $20 \%$ de nível de chefia e $8 \%$ de gerência. Essa maior proporção da demanda por profissionais de nível auxiliar nas empresas de pequeno porte, em comparação com as de grande porte, demonstra similaridade com o encontrado por Oro et al. (2009). O número de anúncios solicitando conhecimentos em normas internacionais aumentou consideravelmente em relação às empresas de pequeno ou médio porte, correspondendo a $11 \%$ das vagas.

Tabela 2 - Vagas por porte das empresas

\begin{tabular}{c|c|c|c|c}
\hline \multirow{2}{*}{ NÍVEIS } & \multicolumn{2}{|c|}{ PEQUENO E MÉDIO PORTE } & \multicolumn{2}{c}{ GRANDE PORTE } \\
\cline { 2 - 5 } & Qtd. & $\%$ & Qtd. & $\%$ \\
\hline Auxiliar & 47 & $82 \%$ & 95 & $72 \%$ \\
\hline Chefia & 6 & $11 \%$ & 26 & $20 \%$ \\
\hline Gerência & 4 & $7 \%$ & 10 & $100 \%$ \\
\hline Total & 57 & $100 \%$ & 131 & \\
\hline
\end{tabular}

Fonte: Dados da pesquisa.

Para $68 \%$ das vagas das empresas de pequeno ou médio porte, os profissionais deveriam possuir conhecimentos referentes à contabilidade geral e tributária, contra $16 \%$ das vagas que solicitavam conhecimentos inerentes à contabilidade gerencial e gestão empresarial. Para Pires, Ott e Damacena (2009), a predominância da demanda de conhecimentos em contabilidade geral e tributária demonstra que essas empresas ainda vêm o contador como um profissional meramente técnico, exercendo funções mais próximas daquelas que caracterizam o "guardalivros". Similarmente ao encontrado por Diaconu el al. (2011), também foi expressiva a demanda por conhecimentos em tecnologia da informação, com forte apelo por experiência em sistemas integrados e planilhas do Microsoft Excel®, correspondendo a 61\% das vagas. Já 30\% dos anúncios solicitavam conhecimentos em áreas não específicas da contabilidade, como contas a pagar e a receber e recursos humanos.

Grande parte das empresas identificadas como de grande porte, solicitaram os conhecimentos em contabilidade gerencial, correspondendo a $44 \%$ dos anúncios, o que demonstra a percepção do mercado quanto ao profissional contábil participante da gestão empresarial. $60 \%$ dos anúncios requeriam conhecimentos de contabilidade geral e tributária, $53 \%$ conhecimentos em tecnologia da informação e $31 \%$ em áreas não específicas da contabilidade, número próximo ao requerido pelas pequenas e médias empresas. Em relação à exigência quanto à experiência anterior, não houve relevante diferença entre os portes das empresas, correspondendo a $71 \%$ para as grandes empresas e $72 \%$ para as pequenas e médias.

\subsection{Vagas/cargos ofertados por empresas multinacionais}

Constatou-se que 43 anúncios declararam ser de empresas multinacionais, correspondendo a $6 \%$ da amostra analisada, proporção inferior ao coletado por Santos et al. (2011) na cidade de Curitiba (PR) e por Almeida e Favarin (2010) em Campinas (SP). Dessas vagas, $72 \%$ advinham de empresas localizadas no Estado do Amazonas, 26\% no Pará e apenas $2 \%$ no Tocantins. Quanto aos níveis hierárquicos, $63 \%$ correspondiam ao nível auxiliar, 25\% ao nível de chefia e $12 \%$ ao nível de gerência.

Em síntese, o Quadro 4 demonstra o ranking dos conhecimentos e habilidades demandados pelas empresas multinacionais localizadas no Norte brasileiro. 
PERFIL DO PROFISSIONAL CONTÁBIL DEMANDADO PELO MERCADO DE TRABALHO: UM ESTUDO NO NORTE DO BRASIL

Quadro 4 - Ranking dos conhecimentos mais exigidos pelas empresas multinacionais

\begin{tabular}{|c|c|c|}
\hline Posição & Habilid. / Conhec. & \% \\
\hline $\mathbf{1}^{\mathbf{0}}$ & Experiência Profissional & $81 \%$ \\
\hline $\mathbf{2}^{\mathbf{o}}$ & Tecnologia da Informação & $58 \%$ \\
\hline $\mathbf{3}^{\mathbf{o}}$ & Contabilidade Geral e tributária & $56 \%$ \\
\hline $\mathbf{4}^{\mathbf{0}}$ & Outros: MBA, disponibilidade e espírito de liderança & $53 \%$ \\
\hline $\mathbf{5}^{\mathbf{0}}$ & Contabilidade Gerencial & $47 \%$ \\
\hline $\mathbf{6}^{\mathbf{0}}$ & Idiomas & $42 \%$ \\
\hline $\mathbf{7}^{\mathbf{0}}$ & Normas Contábeis Internacionais & $26 \%$ \\
\hline $\mathbf{8}^{\mathbf{o}}$ & Áreas não específicas da Contabilidade & $14 \%$ \\
\hline
\end{tabular}

Fonte: Dados da pesquisa.

Nota-se que dentre os conhecimentos mais solicitados destacou-se a tecnologia da informação, em 58\% dos anúncios, confirmando a importância desse conhecimento para os profissionais contábeis, como visto nas pesquisas de Cory e Pruske (2012) e Rai (2012). Em seguida, os conhecimentos mais demandados foram contabilidade geral e tributária em $56 \%$ dos anúncios e contabilidade gerencial em 47\%. Apenas em $14 \%$ dos anúncios as multinacionais solicitavam dos profissionais conhecimentos de áreas não específicas da contabilidade, contudo verificou-se uma relevante proporção de anúncios solicitando conhecimentos relacionados às normas internacionais, correspondendo a $26 \%$ das vagas, corroborando com a associação realizada por Peleias et al (2008).

Também foi expressiva a demanda por profissionais com experiência, totalizando $81 \%$ dos anúncios, contudo em apenas $42 \%$ das vagas eram exigidas outras línguas, com maior destaque para a língua inglesa, proporção inferior ao encontrado por Cardoso, Souza e Almeida (2006) em seu estudo realizado junto às 150 melhores empresas para se trabalhar, classificadas pela revista Você S.A.

Interessante destacar que em $53 \%$ dos anúncios de vagas haviam outras exigências, sendo expressiva a preferência por profissionais com especialização ou MBA, o que indica a preocupação dessas empresas na qualificação dos profissionais contábeis. Também foi relevante a demanda por profissionais com disponibilidade para viagens ou residir em cidades do interior e por profissionais com espírito de liderança.

\subsection{Vagas/cargo por Nível hierárquico}

Do total da amostra, $66 \%$ dos anúncios de vagas de empregos eram destinados a cargos auxiliares, $22 \%$ a cargos de chefia e $11 \%$ a cargos de gerência, conforme demonstrado no Gráfico 1. Resultado similar ao encontrado por Peleias et al. (2008) em estudo na Região Metropolitana de São Paulo, por Pires, Ott e Damacena (2009), na Região Metropolitana de Porto Alegre (RS), Santos et al. (2011) em estudo realizado na Cidade de Curitiba (PR) e por Oro et al. (2009), que analisaram os anúncios de vagas voltadas à controladoria para todo Brasil e encontraram que $64,61 \%$ referiam-se ao nível operacional.

Contudo o resultado desta pesquisa diferenciou-se do encontrado por Souza e Virgilino (2012) no Estado do Rio Grande do Sul. Segundo os autores, 46\% referiam-se a cargos de chefia, 28\% para auxiliar e $27 \%$ para gerência. Cardoso, Souza e Almeida (2006) também obtiveram resultados bastante distintos da atual pesquisa, encontrando 63,6\% para gerência e 36,4\% para chefia nas 150 melhores empresas para se trabalhar da revista Exame (2004).

Para tentar explicar a alta procura por profissionais para o nível auxiliar, Santos et al. (2011) destaca que essa função, voltada à atividade operacional, demanda maior quantidade de pessoas para desempenhá-la, aumentando, assim, a tendência de maior rotatividade. Já para Peleias et al. (2008), esse fato pode ser ocasionado pela preferência das empresas em realizarem 
seus processos seletivos de forma confidencial para cargos de níveis mais altos, não publicando tais vagas em jornais.

Analisando os dados pela fonte da coleta, percebe-se que das vagas para chefia e gerência, $29 \%$ e $38 \%$ dos anúncios, respectivamente, foram divulgados pelos sites de emprego, atingindo com maior facilidade aos profissionais de outras regiões do Brasil. Tal fato pode apontar uma ligação com a pesquisa realizada pelo Sistema FIEAM (2012) que revelou alta importação de profissionais qualificados de outras partes do Brasil para ocuparem cargos nas indústrias no PIM.

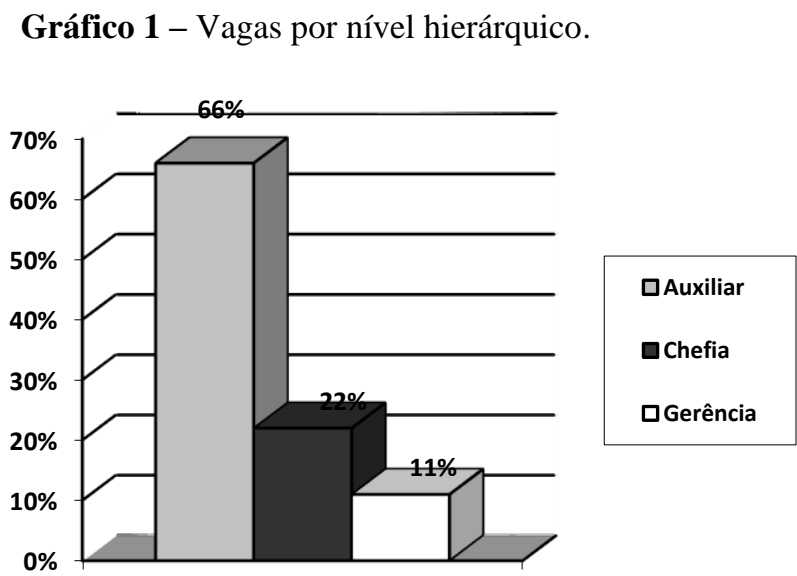

\section{a) Auxiliar}

Fonte: Dados da pesquisa.

Dos cargos destinados ao nível auxiliar, destacam-se os de analista contábil, assistente contábil e estagiários. Apesar desses cargos geralmente se referirem a profissionais em fase inicial da carreira, 75\% dos anúncios exigiam experiência profissional, incluindo os que eram destinados a estagiários. Em seu estudo, Peleias et al. (2008) se depararam com situação similar o que, segundo os autores, pode indicar que as empresas estejam interessadas na redução de investimentos com treinamentos.

Dos conhecimentos solicitados, $63 \%$ referiam-se à contabilidade geral e tributária, 56\% à tecnologia da informação e $34 \%$ a áreas não específicas da contabilidade. Essa mesma ordem de exigência foi encontrada por Santos et al. (2011) em estudo na cidade de Curitiba (PR), sem a realização da distinção dos níveis hierárquicos. Destaca-se, ainda, que $16 \%$ das vagas solicitaram conhecimentos em contabilidade gerencial e $4 \%$ solicitaram conhecimentos referentes às normas contábeis internacionais e convergência das normas brasileiras. Somente $7 \%$ dos anúncios exigiam algum conhecimento em línguas estrangeiras, mesma proporção de vagas destinadas a profissionais com disponibilidade para viagens ou residir no interior dos Estados. Também foram solicitados dos profissionais proatividade, habilidade com matemática financeira, carteira nacional de habilitação, bom relacionamento interpessoal, entre outros. Outro fato encontrado pela pesquisa que corrobora com a dedução de Peleias et al. (2008) quanto à redução de investimentos das empresas em treinamento de seus funcionários, é a exigência em 3\% das vagas de profissionais com especialização ou MBA.

\section{b) Chefia}

Os profissionais do nível de chefia foram procurados principalmente para os cargos de coordenador, supervisor e contador. Por ser tratar de cargos de maior complexidade, $83 \%$ das vagas exigiam vasta experiência nas atividades de atuação, proporção superior à encontrada por Pires, Ott e Damacena (2009) para esse nível hierárquico em Porto Alegre (RS). 
Dentre os conjuntos de conhecimentos, a contabilidade geral e tributária foi a mais solicitada, correspondendo a $70 \%$ das vagas, seguida da tecnologia da informação com $44 \%$, contabilidade gerencial com $34 \%$ e áreas não específicas da contabilidade com $29 \%$. Os conhecimentos voltados às normas internacionais foram solicitados em $9 \%$ dos anúncios, sendo o maior índice nos três níveis hierárquicos desta pesquisa e, ainda, superior ao encontrado por Peleias et al. (2008) em estudo voltado à Grande São Paulo.

Apenas 9\% dos anúncios solicitavam conhecimento em línguas estrangeiras, contudo $20 \%$ das vagas eram destinadas a candidatos com especialização ou MBA. Das habilidades pessoais requeridas destacaram-se o espírito de liderança, a proatividade e o bom relacionamento interpessoal, assim como no estudo que Leal, Soares e Souza (2008) realizaram na cidade de Uberlândia (MG).

\section{c) Gerência}

Em $77 \%$ das vagas do mais alto dos níveis hierárquicos avaliados, foi requerida vasta experiência profissional, com destaque para $11 \%$ de anúncios solicitando experiência acima de quatro anos, chegando até a exigência de mais de 10 anos na função.

$\mathrm{O}$ conjunto de conhecimentos de maior destaque referiu-se à contabilidade gerencial $\mathrm{e}$ gestão empresarial, correspondendo a $82 \%$ das vagas, ficando $54,5 \%$ superior ao encontrado por Peleias et al. (2008) para o cargo de gerência. Em seguida, os conhecimentos em tecnologia da informação e áreas não específicas da contabilidade, corresponderam a $34 \%$ e $23 \%$, respectivamente.

Conhecimentos em contabilidade geral e tributária foram solicitados em apenas $18 \%$ das vagas, destacando que a parte técnica não tem tanta demanda para esse nível hierárquico. Já os conhecimentos em idiomas foram requisitados em $18 \%$ dos anúncios e os conhecimentos voltados às normas internacionais em 5\%, exatamente o mesmo resultado encontrado por Pires Ott e Damacena (2009) para esse nível hierárquico. Similarmente ao nível de chefia, 19\% das vagas para gerência eram destinadas a profissionais com especialização ou MBA, ratificando a necessidade pela educação continuada dos profissionais contábeis. Dentre as habilidades pessoais requisitadas, destacaram-se o espírito de liderança, bom relacionamento interpessoal, proatividade e disponibilidade para viagens ou residir no interior dos Estados.

Em síntese, o Quadro 5 demonstra o ranking dos conhecimentos e habilidades separados por nível hierárquico. Realizando a comparação com o ranking dos conhecimentos mais exigidos na Grande São Paulo (PELEIAS ET AL., 2008), em Porto Alegre (RS) (PIRES; OTT; DAMACENA, 2009) e em Curitiba (PR) (SANTOS ET AL., 2011), concluiu-se que o perfil do profissional contábil solicitado pelo mercado de trabalho do Norte do Brasil detêm uma grande similaridade ao perfil solicitado pelo mercado da Cidade de Curitiba (PR), diferenciando, em alguns itens, dos demais estados. Percebe-se ainda, que apesar de pertencerem a regiões brasileiras distintas, os mercados de trabalho dos estudos supracitados demandam por um profissional eclético, com uma gama de conhecimentos e habilidades, contudo priorizam os conhecimentos voltados à parte operacional e dão menor ênfase aos conhecimentos ligados à tomada de decisão, similar aos resultados encontrados na presente pesquisa. 
Carla Macedo Velloso dos Santos Tamer - Clilson Castro Viana - Luiz Augusto de Carvalho Francisco Soares Mariomar de Sales Lima

Quadro 5 - Ranking dos conhecimentos mais exigidos por nível hierárquico

\begin{tabular}{|c|c|c|c|c|c|c|}
\hline \multirow{2}{*}{ Posição } & \multicolumn{2}{|l|}{ AUXILIAR } & \multicolumn{2}{|l|}{ CHEFIA } & \multicolumn{2}{|l|}{ GERÊNCIA } \\
\hline & Habilid. / Conhec. & $\%$ & Habilid. / Conhec. & $\%$ & Habilid. / Conhec. & $\%$ \\
\hline $1^{\mathbf{o}}$ & $\begin{array}{l}\text { Experiência } \\
\text { Profissional }\end{array}$ & $75 \%$ & $\begin{array}{l}\text { Experiência } \\
\text { Profissional }\end{array}$ & $83 \%$ & $\begin{array}{c}\text { Contabilidade } \\
\text { Gerencial }\end{array}$ & $82 \%$ \\
\hline $2^{\mathbf{o}}$ & $\begin{array}{c}\text { Contabilidade Geral } \\
\text { e tributária }\end{array}$ & $63 \%$ & $\begin{array}{c}\text { Contabilidade Geral } \\
\text { e tributária }\end{array}$ & $70 \%$ & $\begin{array}{l}\text { Experiência } \\
\text { Profissional }\end{array}$ & $77 \%$ \\
\hline $3^{\mathbf{o}}$ & $\begin{array}{l}\text { Tecnologia da } \\
\text { Informação }\end{array}$ & $56 \%$ & $\begin{array}{l}\text { Tecnologia da } \\
\text { Informação }\end{array}$ & $44 \%$ & $\begin{array}{l}\text { Tecnologia da } \\
\text { Informação }\end{array}$ & $34 \%$ \\
\hline $4^{\circ}$ & $\begin{array}{c}\text { Áreas não } \\
\text { específicas da } \\
\text { Contabilidade }\end{array}$ & $34 \%$ & $\begin{array}{l}\text { Contabilidade } \\
\text { Gerencial }\end{array}$ & $34 \%$ & $\begin{array}{c}\text { Outros: } \\
\text { MBA, liderança, } \\
\text { bom relaciona- } \\
\text { mento interpessoal, } \\
\text { proatividade e } \\
\text { disponibilidade. }\end{array}$ & $32 \%$ \\
\hline $5^{\circ}$ & $\begin{array}{c}\text { Outros: } \\
\text { Disponibilidade, } \\
\text { proatividade, MBA, } \\
\text { bom relacionamento } \\
\text { interpessoal, CNH e } \\
\text { matemática } \\
\text { financeira. }\end{array}$ & $17 \%$ & $\begin{array}{c}\text { Outros: } \\
\text { MBA, liderança, } \\
\text { proatividade, bom } \\
\text { relacionamento } \\
\text { interpessoal, } \\
\text { disponibilidade e } \\
\text { CNH. } \\
\end{array}$ & $29 \%$ & $\begin{array}{c}\text { Áreas não } \\
\text { específicas da } \\
\text { Contabilidade }\end{array}$ & $23 \%$ \\
\hline $6^{0}$ & $\begin{array}{l}\text { Contabilidade } \\
\text { Gerencial }\end{array}$ & $16 \%$ & $\begin{array}{c}\text { Áreas não } \\
\text { específicas da } \\
\text { Contabilidade }\end{array}$ & $29 \%$ & $\begin{array}{c}\text { Contabilidade Geral } \\
\text { e tributária }\end{array}$ & $18 \%$ \\
\hline $7^{0}$ & Idiomas & $7 \%$ & Idiomas & $9 \%$ & Idiomas & $18 \%$ \\
\hline $8^{\mathbf{o}}$ & $\begin{array}{l}\text { Normas Contábeis } \\
\text { Internacionais }\end{array}$ & $4 \%$ & $\begin{array}{l}\text { Normas Contábeis } \\
\text { Internacionais }\end{array}$ & $9 \%$ & $\begin{array}{l}\text { Normas Contábeis } \\
\text { Internacionais }\end{array}$ & $5 \%$ \\
\hline
\end{tabular}

Fonte: Dados da pesquisa.

A demanda por experiência ficou em primeiro lugar e as normas contábeis internacionais e convergência das normas brasileiras, apareceram em último lugar na grande maioria dos rankings dessas pesquisas. Tais fatos podem demonstrar que as empresas apresentam pouco interesse no investimento em treinamentos de seus funcionários e que os conhecimentos referentes às normas internacionais já estejam implícitos na demanda pela contabilidade geral e por profissionais experientes.

\subsection{Vagas para outros profissionais e conhecimentos demandados na área contábil}

Assim como no estudo de Pires, Ott e Damacena (2009), observou-se um expressivo número de anúncios de vagas de emprego abertas também para profissionais com outras formações, com destaque à administração, ciências econômicas, direito e engenharia. Do total da amostra, essas vagas correspondem a 38\%, sendo $24 \%$ para o nível auxiliar e $7 \%$ para o nível de chefia e também para o nível de gerência.

Importante destacar que $30 \%$ dessas vagas exigiam algum conhecimento do grupo de contabilidade geral e tributária e 5\% do grupo de normas contábeis internacionais, o que ressalta a necessidade de um profissional da área contábil para ocupar tais cargos.

Para as 457 vagas destinadas aos profissionais de nível auxiliar, 164 não eram direcionadas apenas para os profissionais contábeis, correspondendo a $36 \%$ das vagas. Já para o nível de chefia e de gerência, essas vagas corresponderam, respectivamente, a 33\% e 62\%, indicando uma proporção superior aos encontrados pelos autores supracitados no estado. 


\section{CONSIDERAÇÕES FINAIS}

Este artigo objetivou identificar o perfil do profissional contábil demandado pelo mercado de trabalho do Norte do Brasil, segundo os anúncios de emprego divulgados em sites de recrutamento e jornais de grande circulação. Com a análise de 690 anúncios e a elaboração de um ranking dos conhecimentos e habilidades mais exigidos pelo mercado de trabalho do Norte, foi possível perceber a procura por um profissional eclético, com uma gama de conhecimentos e habilidades, contudo prioriza os conhecimentos voltados à parte operacional nos níveis de auxiliar e chefia, em $63 \%$ e $70 \%$ das vagas, respectivamente. Já para os cargos de gerência, a primeira posição correspondeu à contabilidade gerencial (82\%).

Observou-se, ainda, a expressiva demanda por profissionais com experiência, ficando nas primeiras posições em todos os níveis hierárquicos, como em Peleias et al. (2008) em São Paulo, Pires, Ott e Damacena (2009), em Porto Alegre (RS) e Santos et al. (2011), em Curitiba (PR). Além disso, conhecimentos voltados à tecnologia da informação, áreas não específicas da contabilidade e cursos de especialização ou MBA foram bastante exigidos pelo mercado, diferentemente do conhecimento em idiomas e em normas contábeis internacionais, que ocuparam, respectivamente, a penúltima e última posição do ranking, em todos os níveis. A baixa demanda por conhecimentos em normas contábeis internacionais pode demonstrar que tais conhecimentos já estejam implícitos na demanda pela contabilidade geral e por profissionais experientes.

Dos anúncios que identificaram o porte da empresa, $70 \%$ correspondiam a empresas de grande porte e $30 \%$ de pequeno e médio. Os conhecimentos referentes à convergência das normas brasileiras com as internacionais foram encontrados em $11 \%$ das vagas para grandes companhias, contra $2 \%$ para pequenas e médias. Também, os conhecimentos voltados para a contabilidade gerencial tiveram maior proporção nas grandes empresas, correspondendo a $44 \%$ dos anúncios, contra $16 \%$ das de pequeno e médio porte. Esse resultado demonstrou que as grandes empresas da região vêem o profissional contábil como parceiro do negócio, reconhecendo sua importância para a tomada de decisão.

Já para as empresas multinacionais, que foram identificadas em 6\% da amostra, notouse uma demanda por profissionais ecléticos, com o perfil voltado também para a gestão da empresa. A exigência dos conhecimentos em tecnologia da informação representou $58 \%$ da amostra, destacando a importância desse conhecimento para os profissionais contábeis, assim como visto nos estudos de Cory e Pruske (2012) e Rai (2012). Do total das vagas, $42 \%$ exigiam idiomas, com maior destaque para o inglês, e $23 \%$ exigiam especialização ou MBA, corroborando com as conclusões de Kavanagh et al. (2010)..

Também foi possível identificar com esta pesquisa a grande proporção de vagas destinadas a profissionais de outras áreas, como administradores, economistas, advogados e engenheiros, correspondendo a $38 \%$ do total da amostra. Esse fato preocupa por ser identificado que $30 \%$ dessas vagas solicitavam conhecimentos em contabilidade geral e tributária e 5\% em normas contábeis internacionais e convergência das normas brasileiras, conhecimentos inerentes aos profissionais da área contábil.

Neste viés, a análise do estudo pode ser aplicada, não somente para identificar o perfil do profissional contábil demandado pelo mercado de trabalho do Norte do Brasil, mas também é importante fonte para a definição dos currículos universitários e agenda de eventos voltados à capacitação e atualização dos profissionais contábeis na região. Com isso, os profissionais poderão se adequar à demanda das empresas e, por conseguinte, as empresas terão maior acesso a profissionais locais mais capacitados, diminuindo a necessidade da importação de mão de obra de outras regiões brasileiras.

Como recomendação para futuras pesquisas, sugere-se a comparação das demandas apresentadas neste estudo com as grades curriculares das instituições de ensino superior (IES) 
do Norte brasileiro, indicando se os profissionais que estão sendo formados na região atendem ao perfil solicitado pelas empresas. Segere-se, ainda, a realização de pesquisas com foco no tema da educação continuada junto aos contadores atuantes no mercado do Norte brasileiro, a fim de investigar o nível de atualização desses profissionais e os meios usados para essa atualização.

\section{REFERÊNCIAS}

ALMEIDA, Fábio S.; FAVARIN, Antonio M. Sistemas de Informações Gerenciais - o ambiente empresarial e o perfil do profissional de contabilidade. In: CONGRESSO USP DE CONTABILIDADE E CONTROLADORIA, 7. , 2007, São Paulo, Anais... São Paulo: USP, 2007.

BLOUCH, William E.; ULRICH, Thomas A.; MICHENZI, Alfred R. Enhancing Student Nontechnical Professional Business Skills: An Academic Based Socialization Program. In: ASBBS 2010 ANNUAL CONFERENCE. Proceedings... 2010. p. 320-333.

BRASIL. Lei $\mathbf{n}^{\mathbf{0}}$ 11.638/2007: Altera e revoga dispositivos da Lei ${ }^{\circ}$ 6.404, de 15 de dezembro de 1976. Disponível em: <http://www.planalto.gov.br/ccivil_03/_ato20072010/2007/lei/l11638.htm>. Acesso em: 02/06/2012.

Lei no 11.941/2009: Altera a legislação tributária federal relativa ao parcelamento ordinário de débitos tributários (...) e dá outras providências. Disponível em: < http://www.planalto.gov.br/ccivil_03/_ato2007-2010/2009/lei/111941.htm>. Acesso em: 02/06/2012.

Lei no 6.404/76: Dispõe sobre as Sociedades por Ações. Disponível em: <http://www.planalto.gov.br/ccivil_03/leis/16404compilada.htm>. Acesso em: 02/06/2012.

. Ministério da Educação. Resolução CFE n 3, de 3.10.1992. Fixa os mínimos de conteúdo e duração do curso de graduação em Ciências Contábeis.

CARDOSO, Jorge Luiz; SOUZA, Marco Antônio de; ALMEIDA, Lauro Brito. Perfil do contador na atualidade: um estudo exploratório. Revista de Administração e Contabilidade da Unisinos, Porto Alegre, v. 3, n. 3, p. 275-284, set./dez. 2006.

CATHO. Ofertas de emprego. Disponível em: <http://catho.com.br> Acesso em: 14/10/2012.

CHAKER, Mohammed Naim; ABDULLAH, Tengku Akbar Tengku. What accountancy skills are acquired at college. International Journal of Business and Social Science, v. 2, p. 18, 2012.

\section{CONSELHO FEDERAL DE CONTABILIDADE. Resolução CFC nº 1.055/05.}

CORY, Suzanne; HUTTENHOFF, Thomas. Perspectives of non-public accountants about accounting education and certifications: An exploratory investigation. Journal of Finance and Accountancy, v. 6, n. 3, p. 1-14, 2011.

CORY, Suzanne N.; PRUSKE, Kimberly A. Necessary Skills for Accounting Graduates: An Exploratory Study to Determine What the Profession Wants. Proceedings of the American Society of Business and Behavioral Sciences, v. 19, n. 1, p. 208-218, 2012. 
DIACONU, Paul et al. The needs of the financial labour market in Romania and the answer of the local universities to this social demand. Journal of Accounting and Management Information Systems, v. 10, n. 1, p. 55-73, 2011.

FARIA, Ana Cristina de; et al. SPED - Sistema Público de Escrituração Digital: Percepção dos contribuintes em relação os impactos da adoção do SPED. Disponível em: < http://www.congressousp.fipecafi.org/artigos102010/248.pdf>. Acesso em: 25/06/2012.

FARIA, Ana Cristina; QUEIROZ, Mario Roberto Braga de. Demanda de profissionais habilitados em contabilidade internacional no mercado de trabalho da cidade de São Paulo. Revista Universo Contábil, Blumenau, v. 5, n. 1, p. 55-71, jan./mar. 2009.

IBGE - INSTITUTO BRASILEIRO DE GEOGRAFIA E ESTATÍSTICA. 2010. Perfil dos Estados. Disponível em: <http://www.ibge.gov.br>. Acesso: 19/10/2012.

INDEED. Ofertas de emprego. Disponível em: <http://indeed.com.br> Acesso em: $14 / 10 / 2012$.

KAVANAGH, Marie et al. Who should teach what? Perceptions of the roles of universities and practice in the education of professional accountants. In: AFAANZ Conference. Accounting \& Finance Association of Australia and New Zealand, 2010. Proceedings..., 2010 p. 1-25.

LEAL, Edvalda Araujo; SOARES, Mara Alves; SOUZA, Edileusa Godói. Perspectivas dos formandos do curso de Ciências Contábeis e as exigências do mercado de trabalho. Revista Contemporânea de Contabilidade, Recife, v. 1, n. 10, p. 147-159, jul./dez. 2008. http://dx.doi.org/10.5007/2175-8069.2008v5n10p147

MACHADO, Vinicius Sucupira de Alencar; NOVA, Silvia Pereira de Castro Casa. Análise comparativa entre os conhecimentos desenvolvidos no curso de graduação em contabilidade e o perfil do contador exigido pelo mercado de trabalho: uma pesquisa de campo sobre educação contábil. Revista de Educação e Pesquisa em Contabilidade, Brasília, v. 2, n.1, p. 01-23, jan./abr. 2008.

MCMULLEN, Dorothy A.; SANCHEZ, Maria H. A Preliminary Investigation of the Necessary Skills, Education Requirements, and Training Requirements for Forensic Accountants. Journal of Forensic \& Investigative Accounting, v. 2, n. 2, p. 30-48, 2010.

ORO, Ieda Margarete; et al. O perfil do profissional de controladoria sob a óptica do mercado de trabalho brasileiro. Revista Pensar Contábil, Brasília, v. 11, n. 44, p. 5-15, abr./jun. 2009.

PELEIAS, Ivam Ricardo; et al. Identificação do perfil profissiográfico do profissional de contabilidade requerido pelas empresas, em anúncios de emprego na Região Metropolitana de São Paulo. Base - Revista de Administração e Contabilidade da Unisinos, Porto Alegre, v. 5, n. 2, p. 131-141, maio/ago. 2008. http://dx.doi.org/10.4013/base.20082.05

PIRES, Charline Barbosa; OTT, Ernani; DAMACENA, Claudio. "Guarda-Livros" ou "Parceiros de Negócios"? Uma Análise do Perfil Profissional Requerido pelo Mercado de Trabalho para Contadores na Região Metropolitana de Porto Alegre (RMPA). Revista Contabilidade Vista \& Revista, Belo Horizonte, v. 20, n. 3, p. 157-187, jul./set. 2009. 
RAI, Pranish. Matching up the gap between perceived importance and knowledge for IT skills among Australian accountants. In: System Science (HICSS), 2012 45th Hawaii International Conference on. IEEE, 2012. p. 3632-3640.

SANTOS, Daniel Ferreira dos; et al. Perfil do profissional contábil: estudo comparativo entre as exigências do mercado de trabalho e a formação oferecida pelas instituições de ensino superior de Curitiba. Revista Contemporânea de Contabilidade - UFSC, Florianópolis, v. 8, n. 16, p. 137-152, jul./dez. 2011. http://dx.doi.org/10.5007/2175-8069.2011v8n16p137

SANTOS, Edilene Santana. Full IFRS x Lei 11.638 ( $1^{\text {a }}$ fase) x Lei 6.404: impacto esperado nos resultados de 2010 a partir das empresas que se anteciparam. In: CONGRESSO USP DE CONTROLADORIA E CONTABILIDADE, 11, 2011, São Paulo, Anais... São Paulo: USP, 2011, p. 1-17.

SISTEMA FIEAM. Pesquisa aponta carência de mão de obra qualificada na indústria. Desenvolvida por PIEROSAN, Genoir; MELLONI, Ocimar. Disponível em: $<$ http://www.fieam.org.br/site/fieam/pesquisa-aponta-carencia-de-mao-de-obra-qualificadana-industria/>. Acesso em: 25/10/2012.

SOUZA, Marcos Antonio de; VERGILINO, Caroline da Silva. Um perfil do profissional contábil na atualidade: estudo comparativo entre conteúdo de ensino e exigências de mercado. Disponível em: < https://www.furb.br/especiais/download/866027-657185/EPC\%2092.pdf>. Acesso em: 21/06/2012.

STARKE JÚNIOR, Paulo César; FREITAG, Viviane da Costa; CROZATTI; Jaime. A função social da pesquisa em contabilidade. In: Seminário de Ciências Contábeis, 2. Blumenau, SC, p. 1-13, 22 a 24 de agosto de 2006 Anais.... 2006. Disponível em: <http://www.dcc.uem.br /semana2006/anais2006/Anais_2006_arquivo_01.pdf.> Acesso em: 11/10/2012.

VERGARA, Sylvia Constant. Métodos de pesquisa em administração. 4. ed. São Paulo: Atlas, 2010. 274 p. 